\title{
FUNCTIONAL ASPECTS OF MODERN WIRELESS NETWORKS IN INDUSTRIAL ENVIRONMENT
}

\author{
Piotr Szulewski
}

S u m m a r y

The use of the radio controlled network system in industrial tasks is a real fact. The new medium, according to its nature and characteristics improves new possibilities in the data transfer. The paper illuminates some basic problems concerning the wireless communication systems. Attributes and limitation are simply presented. Some rules and recommendations are formulated and elaborated. Three popular wireless standards (from ISM band) were used as an applicable example. The newest evolution conception of industrial wireless standards was pointed out.

Keywords: wireless, network, industrial, information integration

Możliwości funkcjonalne stosowania sieci bezprzewodowych w środowisku przemysłowym

$$
\text { S treszczen i e }
$$

Używanie sieci bezprzewodowych w środowiskach przemysłowych jest już powszechne. Ten nowoczesny środek komunikacji, ze względu na swoje właściwości, pozwala na wprowadzanie nowych metod przesyłania danych. W pracy przedstawiono podstawowe problemy pojawiające się przy bezprzewodowych systemach transmisji danych. Podano ograniczenia i główne cechy tej formy komunikacji. Przeprowadzono analizę problemów i przedstawiono niezbędne wymagania i zalecenia w tym zakresie. Omówiono przykłady trzech głównych standardów pracujących w paśmie nielicencjonowanym (ISN). Wskazano na nowe kierunki rozwoju standardów bezprzewodowych.

Słowa kluczowe: bezprzewodowy, sieć, przemysłowy, łączenie danych, warsztat

\section{Introduction}

The modern manufacturing systems (like machine tools, robots, technological equipment, assembling lines, etc.) are controlled by programmable numeric controllers (PLC, NC, CNC) or industrial computers. The computation and processing of digital information is the basement for the present control and monitoring systems. This situation is sometimes called an information cloud or information distribution. Up to this time, the information source was stationary

Address: Piotr SZULEWSKI, PhD. Eng., Warsaw University of Technology, Faculty of Production Engineering, Narbutta 86, 02-524 Warsaw, Poland, e-mail: maxer@cim.pw.edu.pl 
and place mounted. The wireless technologies changed it diametrically. The wireless communication systems set the new meaning of real mobile data interchange.

According to the results presented in the literature the main application for networks in industrial environment are supervisory control and data acquisition. The effective communication network should transmit all data generated by SCADA (Supervisory Control and Data Acquisition) like diagnostics, testing, maintenance, motion control, robotic, etc. [1].

\section{Requirements and properties}

The wireless systems are accomplished through the use of electromagnetic waves. A radio wave can oscillate (in general) at frequencies between $3 \mathrm{kHz}$ and $100 \mathrm{GHz}$ [2]. According to the rules and regulations, the full radio spectrum is broken down into multiple sections, designed for private use (HAM), government use or considered to be unlicensed and free for all users (for example extremely popular Citizen Band (CB radio) frequency from 26.965$-27.405 \mathrm{MHz}$. All radio standards are elements of Electric and Electronic Engineers (IEEE) official publications. Please refer to Fig. 1, where some main wireless industrial standards are simply presented (also their intended coverage areas and corresponding bit rates). According to the practice and publication, the main four types of wireless areas are described (PAN-personal area network, LAN-local area network, MAN-metropolitan area network, Wan-wide area network). From the industrial point of view the most interesting are PAN and LAN, due to the distance usually occurred in the traditional workshop [3]. Some basic information about mentioned standards will be lightly elaborated in Tables 1,2 and 3.

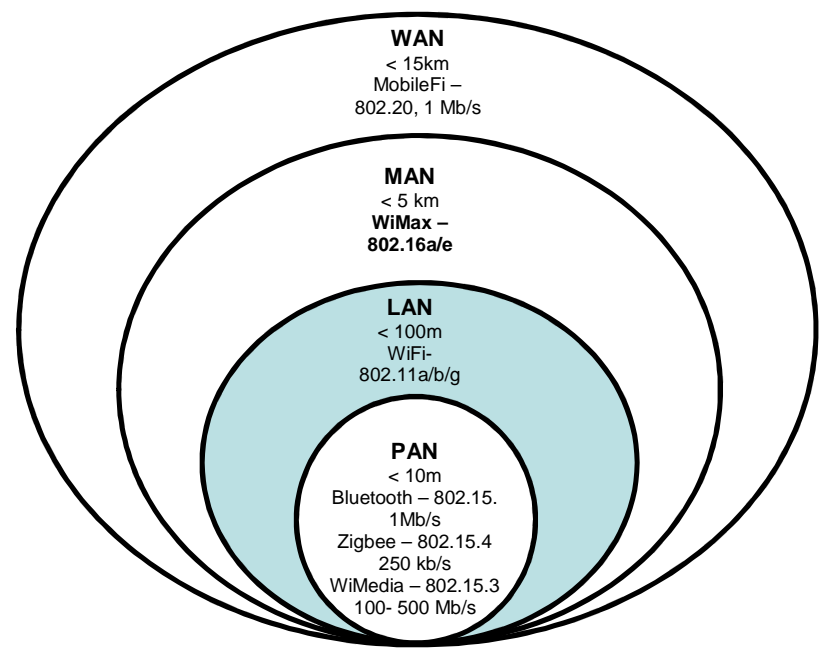

Fig. 1. Wireless network standards 
Functional aspects of modern wireless networks ...

Table 1. The key characteristics of Zigbee, Wi-Fi and Bluetooth (ISM band)

\begin{tabular}{|c|c|c|c|}
\hline Parameters & ZigBee & Wi-Fi & Bluetooth \\
\hline Max. Signal rate & $250 \mathrm{~KB} / \mathrm{s}$ & $54 \mathrm{MB} / \mathrm{s}$ & $1 \mathrm{MB} / \mathrm{s}$ \\
\hline Networking Topology & $\begin{array}{l}\text { Ad-hoc, peer to peer, } \\
\text { star, or mesh }\end{array}$ & Point to hub & $\begin{array}{c}\text { Ad-hoc, very small } \\
\text { networks }\end{array}$ \\
\hline Operating Frequency & $\begin{array}{c}868 \mathrm{MHz} \text { (Europe) } \\
900-928 \mathrm{MHz} \text { (NA), } \\
2.4 \mathrm{GHz} \text { (worldwide) }\end{array}$ & 2.4 and $5 \mathrm{GHz}$ & $2.4 \mathrm{GHz}$ \\
\hline Nominal TX power & $(-25) \div 0 \mathrm{dBm}$ & $15 \div 20 \mathrm{dBm}$ & $0 \div 10 \mathrm{dBm}$ \\
\hline Number of channels & $1 / 10,16$ & 14 & 79 \\
\hline Security & $\begin{array}{l}128 \text { AES plus } \\
\text { application layer } \\
\text { security }\end{array}$ & & $\begin{array}{l}64 \text { and } 128 \text { bit } \\
\text { encryption }\end{array}$ \\
\hline Data protection & 16 bit CRC & 32 bit CRC & 16 bit CRC \\
\hline Number of nodes & 65000 & 2000 & 8 \\
\hline
\end{tabular}

Table 2. The quick overview of the functionality differences between the main wireless technologies

\begin{tabular}{|c|c|c|c|c|}
\hline Parameters & $\begin{array}{c}\text { Bluetooth } \\
\text { technology }\end{array}$ & $\begin{array}{c}\text { Wireless LAN / } \\
\text { WLAN }\end{array}$ & $\begin{array}{c}\text { ZigBee / } \\
\text { IEEE 802.15.4 }\end{array}$ & $\begin{array}{c}\text { Bluetooth low } \\
\text { energy technology }\end{array}$ \\
\hline Data throughput & $\mathrm{O}$ & ++ & - & - \\
\hline Robustness & ++ & $+/-$ & $+/-$ & ++ \\
\hline Range (m) & $10-1000$ & $50-300$ & $75+$ mesh & $10-300$ \\
\hline Local system density & ++ & - & $+/-$ & ++ \\
\hline Roaming & + & ++ & N/A & N/A \\
\hline Large scale network & - & $+/-$ & ++ & ++ \\
\hline Low latency & ++ & $+/-$ & + & ++ \\
\hline Connection set-up speed & - & $+/-$ & ++ & +++ \\
\hline Power consumption & + & - & + & ++ \\
\hline Cost & + & - & & + \\
\hline
\end{tabular}

The deployment of wireless systems in the office (home) environment over the past decade has been remarkable. Beginning from simple cordless technology (telephone) up to the fast data transfer structures. This situation is fully justified. But industrial environment is uniquely different from office or home environment. For example: high temperatures, excessive airborne particulates, multiple obstacles, vibrations and long distances separating equipment and systems. These characteristics are special challenges that make it difficult to place and reach computers, controllers, NC, sensors, transmitters and other data communication devices. In other words it is a really harsh environment for electromagnetic propagation [4]. 
Table 3. The main advantages and disadvantages of the popular wireless solutions (ISM band)

\begin{tabular}{|c|c|c|}
\hline Standard & Advantage & Disadvantage \\
\hline $\begin{array}{c}\text { WiFi (IEEE } \\
802.11 \mathrm{~b} / \mathrm{g} / \mathrm{n}\end{array}$ & $\begin{array}{c}\text { Really open standard for home and office, } \\
\text { widely used all over the world, high data } \\
\text { transfer, inexpensive components }\end{array}$ & $\begin{array}{c}\text { Requires excessive overhead in terms } \\
\text { of power consumption, complicated } \\
\text { software, processor resources, short } \\
\text { distance, large size of physical } \\
\text { components }\end{array}$ \\
\hline Bluetooth & $\begin{array}{c}\text { Really small size of transmitter/receiver, } \\
\text { instant network setup, large network }- \\
\text { external bridge eliminated at all, }\end{array}$ & $\begin{array}{c}\text { Relatively high data cycle, nor effective } \\
\text { data throughput, needs line-of-site (due to } \\
\text { is not free from drawback in its binding } \\
\text { methodologies, especially in situation } \\
\text { when several similar nodes try to connect } \\
\text { to the similar access points. }\end{array}$ \\
\hline & $\begin{array}{c}\text { Power friendly (sleep and sniff abilities), } \\
\text { very good penetration ability, extremely } \\
\text { small footprint size - for mobile and } \\
\text { battery powered equipment }\end{array}$ & $\begin{array}{c}\text { Low data races (up to 720 kbit/s), rather } \\
\text { poor interoperability, }\end{array}$ \\
\hline
\end{tabular}

Depending of the application, the most important factors required in industrial wireless solutions should be specified as follows:

- support for real-time applications (especially for time critical),

- reliability (it means providing reliable radio channels),

- interoperability (all standard interfaces and protocols have to be open and well documented),

- high security level (better or not less than traditional wired system),

- robustness (i.e. against electromagnetic interference from engines, machinery and electronic equipment),

- easy configuration (like plug and play),

- low costs (equipment purchase, installation and maintenance).

Analyzing radio communication features for industrial application, some main advantages can be observed and specified:

- increase mobility of any manufacturing equipment (stable and mobile),

- decentralization of automation functions (real DCS),

- it is very easy and cheap to overcome large zones (i.e. wide workshop),

- practically, all expensive transmission media (cables, hubs, switches, etc.) may be completely removed,

- applicable for moving and rotating equipment,

- really fast and efficient installation,

- maintenance cost could be reduced or eliminated completely,

- improved fault localization and isolation,

- development of micro-electromechanical systems (MEMS) with integrated built-in sensors, 
- small, light (battery operated) and convenient human interface devices (HID) should be used to stay in tough with supervisory control systems.

The modern wireless network standards can be divided into two classes relating to its frequency band. The first, (i.e. WiFi) operates in the ISM band $(2,4 \mathrm{GHz})$, the second (i.e. WiMax) operates in the higher frequency band ( $5 \mathrm{GHz}$, microwave). The only ISM band is presented of this paper, due to the low cost and popularity. The ISM band (industrial, scientific, medical) is a span of frequencies in the $2,4 \mathrm{GHz}$ range (precisely from $2,4 \div 2,4835 \mathrm{GHz}$ ). It is completely free (no any fees/charges are required) and unlicensed. It can be used by anyone to transmit information wireless. There is only one limitation - digital transmission has to be used on this band (no voice or analog transmission is acceptable) [5]. The channel assignments are presented in Fig. 2.

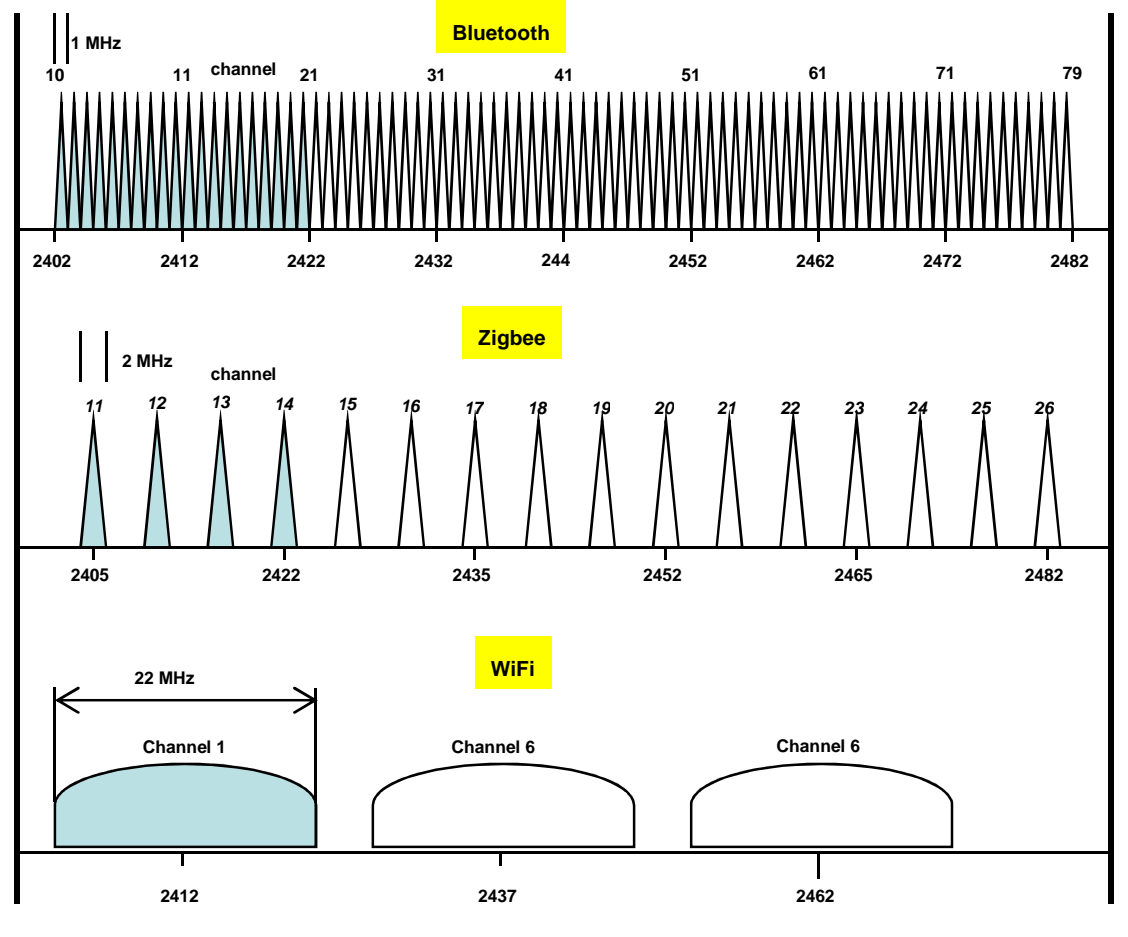

$2400 \mathrm{MHz}$

Fig. 2. The channel assignments for ISM band [5]

There is no one wireless solution which offers the features and strengths mentioned above. In other words no universal standard to fit such various industrial application requirements [6]. The main requirement for this kind of 
communication systems are high data throughput, robustness and low power consumption (i.e. battery operated devices).

In fact, one of the most common problems for wireless systems in the industrial environment is primarily electromagnetic interference (EMI) [7]. It comes from electric motors, industrial processes, computers, drives, other transmitters, etc. According to the experience and known literature elaborations, the EMI interference should be classified in two different categories. They can be called as a broadband and narrowband. Broadband interference signals have a constant energy spectrum over all frequencies and high energy. The narrowband interference signals have less energy. Additionally, the broadband interferences are usually emitted unintentionally from radiating sources. The narrowband interferences are intentional [8]. The general sources of broadband and narrowband found in the industry are presented in the Tab. 4.

Table 4. Interference sources

\begin{tabular}{|c|c|}
\hline \multicolumn{2}{|c|}{ Interferences } \\
\hline broadband & narrowband \\
\hline Motors & Cellular telephone \\
\hline $\begin{array}{c}\text { Circuits } \\
\text { Inverters, Silicon-controlled rectifier (SCR) }\end{array}$ & Radio and TV transmitters \\
\hline Electrical switch contacts & Power-line hum \\
\hline Computers, ESD & Signal generators \\
\hline Ignition systems & Local oscillator, UPS system \\
\hline Voltage regulators & Microwave \& Ultrasonic equipment \\
\hline Lightning electromagnetic pulses & Electronic ballasts \\
\hline Arc/vapor lamps & Medical equipment \\
\hline Pulse generators & Microprocessor systems \\
\hline Thermostats & Pager transmitters \\
\hline Welding equipment & High-frequency generators \\
\hline Frequency converters &
\end{tabular}

Other types of interference sources are, for example, wide operating temperatures, strong vibrations and airborne contaminants [9]. It is important to study and understand the radio channel characteristics in order to predict the communications performance in these operating conditions. Figure 3 presents, as an example, the electromagnetic noise in a factory workshop as a frequency spectrum diagram.

We can define several reasons for disturbing or even stop data flow over wireless networks:

- Echo - typical radio frequency $(2,4 \mathrm{GHz}$ for ISM band) has a good penetration rate through popular construction materials like drywall, wood, plastic. But it was used to bounce off from larger objects made of metals and 
concrete (and it's mixture). It effects redirection the data signal and return it to the transmitter. It causes "echo" or "multi-path" propagation. Especially the multiple reflection can be expected to be high in industrial environment [10].

- Noise - the ineligible electromagnetic emission from different sources. The transmitters and remote nodes are unable to "hear" each other. The effect is a data loss or data retransmission.

- Channel sharing - Many radio communication standards use the same frequency spectrum (please refer to the Fig. 2). The space is enormously crowded. Different nodes and receivers use the same radio channel frequently. The sent information are confused and need a quick retransmission.

- Distance - the physical distance between transmitter and remote node is affected as signal power reducing (according to the known rules, for example WWiedeński formula). The distance could be enlarged in the case of higher transmit power, receiver higher sensitivity or when the receiver/transmitter line of sight (LOS) is assured.

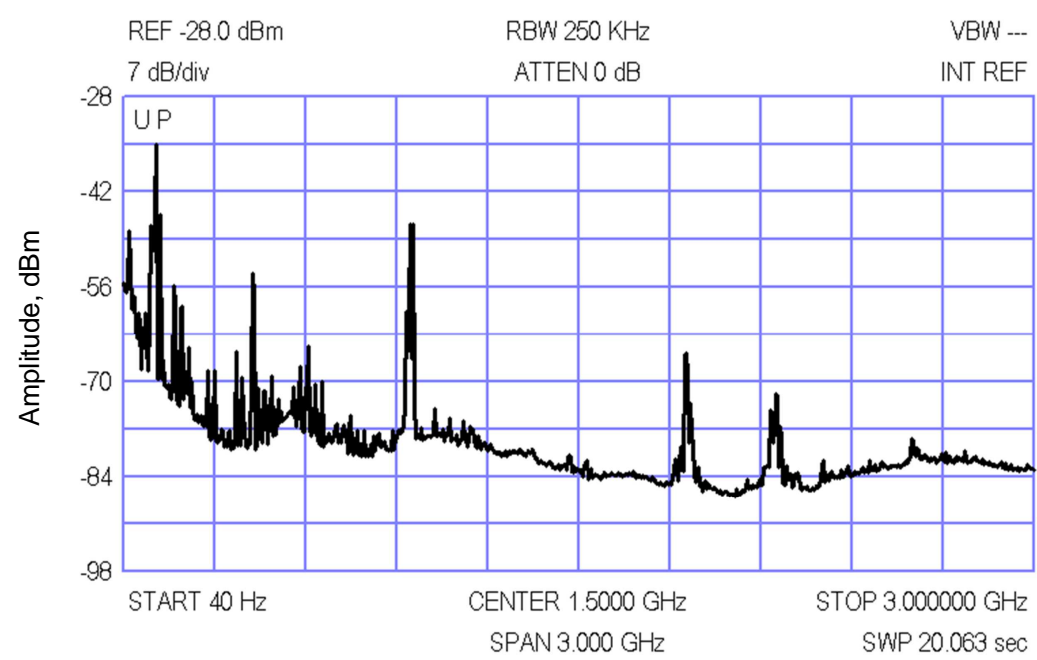

Fig. 3. The frequency spectrum of the electromagnetic noise

All mentioned disturbances can produce the dangerous delays in communication due to retransmission, re-synchronization and data loss. In the worst case it can stop transmission at all. It is not acceptable, especially for the safety reason, when critical real time data could not be delivered in the required time [11].

Fortunately, the new technologies and transmission methods (i.e. FHSS or DSSS) overcome industrial environmental challenges. New spread spectrum radio modulation techniques are applied to reduce interferences because of their multiple access, anti-multipath fading and anti-jamming capabilities. In fact, 
greatly reduces echo, noise and channel sharing issues. The brief description of this scheme is presented below:

- FHSS - (Frequency Hopping Spread Spectrum), single channel is used for data transmission but channel frequency is rapidly and constantly changing or "hopping". The main advantage is the requirement of low bandwidth,

- DSSS - (Direct Sequence Spread Spectrum), the opposite to the FHSS, this method uses several channels. Data is transmitted simultaneously over every available channel - at the same time. The transmission is more reliable in "noisy" environments (especially industrial). The main disadvantage is requirements of high bandwidth.

Of course, moreover, radio modulation techniques can be applied to reduce the interferences. They have different physical mechanisms and therefore, react differently in industrial settings. It should be selected due to the specific application requirements.

\section{The new WiFi conception}

Following the success of cellular telephone services in the 1990s, the technical community has turned its attention to wireless data transmission. Throughput is a key measure of the quality of a wireless data link. It is defined as the number of information bits received without error per second and we would naturally like to achieve this quantity as high as possible.

In fact, the highest effective throughput is the most wanted attribute in all communication systems. Usually, especially in popular meaning, the throughput is called a transmission speed (but not correctly, because the speed should be implied as a synonym of signal propagation). The throughput of a data communications system is not a trivial and depends on a number of variables. But basically, the main rule is illuminated by information theory. According to the well known law, formulated by Claude Shannon, the maximum rate (throughput) at which information can be transmitted over a communication channel depends on the specified bandwidth in the presence of noise. The adequate equation formula is:

$$
C=B \cdot \log _{2}\left(1+\frac{S}{N}\right)
$$

where: $C$ is the throughput (else channel capacity), bit/s; $B$ is the modulated signal bandwidth, $\mathrm{Hz} ; S$ is the received signal power, $\mathrm{W}$ or $\mathrm{V}, N$ is the total noise power over the bandwidth, measured in watt or volt, $S / N$ is the signal-to-noise ratio (SNR). 
This relationship is appropriate for all communication standards and techniques, also for wireless. Wireless communication using one of three strategies for real increasing the throughput:

- higher modulation schemes,

- wider channel bandwidth,

- more spatial streams.

Unfortunately, these strategies need special conditions to enhance the transmission effective throughput. As a matter of fact, the higher modulation scheme should be used in a high signal-to-noise ratio (SNR) environments. It is really hard to achieve such a condition in an industrial workshop, where strong and multi-frequency electromagnetic fields exist. The improvement of channel bandwidth means that the high frequency carrier should be used. In fact, modern WLAN transmission is realized on microwave frequencies $(\mathrm{GHz})$. Problems with stable, effective propagation inside buildings (especially with ferroconcrete construction) are observed and reported. Spatial streams need special transmitters (equipped with several antenna systems) and very sophisticated manipulations to avoid harmful wave interferences [12]. It seems to be that these requirements stay in an opposite way (to each other) and it is very complicated to meet them all together. According to presented examples the general observation should be formulated: there is no easy way to achieve the increase throughput in WLAN techniques.

Please find some more technical information about the latest evolutions of WLAN. These information are set together in Tab. 5. It should be note to focus attention on modulation and antenna system. The new standard uses more sophisticated modulation (256 phase points) and really complicated antenna structure (8 radiators).

Table 5. Continuous development of WLAN standard

\begin{tabular}{|c|c|c|c|}
\hline & $\mathbf{8 0 2 . 1 1}$ a/g & $\mathbf{8 0 2 . 1 1 n}$ & $\mathbf{8 0 2 . 1 1}$ ac \\
\hline Antenna system & $1 \times 1$ SISO & $4 \times 4$ MIMO & $8 \times 8$ MIMO \\
\hline Modulation type & BPSK to 64-QAM & BPSK to 64-QAM & BPSK to 256-QAM \\
\hline Channel bandwidth & $20 \mathrm{MHz}$ & $20 \mathrm{MHz}$ and $20+20 \mathrm{MHz}$ & $\begin{array}{c}20,40,80,80+80 \text { and } \\
160 \mathrm{MHz}\end{array}$ \\
\hline Year introduced & $\begin{array}{c}1999(802.11 \mathrm{a}) \\
2003(802.11 \mathrm{~g})\end{array}$ & 2009 (draft) & 2012 (estimated) \\
\hline
\end{tabular}

\section{The future WLAN application}

As a new conception in automation network the wireless meshed strategies should be presented. Simply, it allows redundant data paths with which the loss of individual connections (meshes) can be compensated fully automatically. The use of wireless LAN technology in conjunction with meshed networking can 
allow operation in environments where cable trays would be difficult or uneconomical to install. The time critical task should be also realized.

The modern wireless sensor networks (WSN) are able to work using different topologies for maximum efficiency and flexibility. The possible topologies include star (single-hop), mesh (multi-hop) and hybrid (cluster-tree) are presented in Fig. 4. The hybrid architecture (c) attempts to combine the low power and simplicity of the star topology (a) as well as the longer range and selfhealing of the mesh (b) network [6].
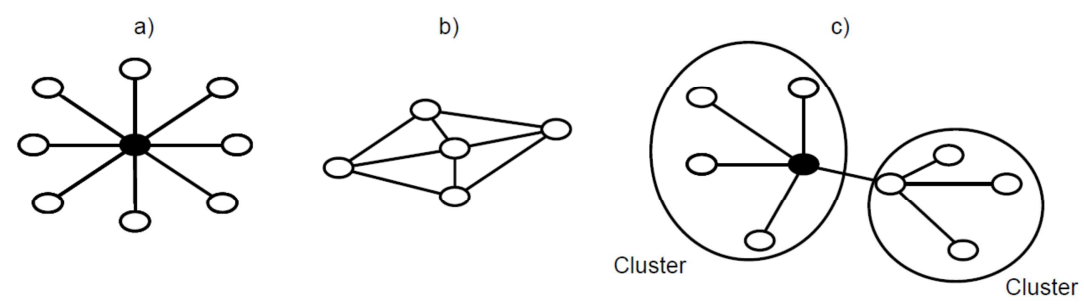

Fig. 4. The new hybrid topology

It is important to recognize also the new possibilities of WLAN, besides the ordinary communication. In fact, the increasing wireless communication (especially WLAN) deployment in industrial environments opens the localization of people, robots, end-devices, etc. This localization process (without using GPS tracking system) offers the position tracking of valuable assets for store-maintenance, the localization of emergency calls, workflowoptimization. It also can be effectively used to increase safety (operation of mobile robots will be allowed only in proximity), increase productivity fast finding the closest way to required components, etc. As described in the competent literature the preliminary evaluation achieves an average accuracy of $3 \mathrm{~m}$ (without any additional sensors and extra fees or charges) [13].

\section{Conclusions}

It should be expected, that the role of wireless communication systems in industrial environment will be more and more significant in the nearest future. But, due to the nature of wireless propagation some sophisticated research are strictly needed and useful. After detailed analyzing of the working installations, intelligent conclusions should be formulated. The rules, recommendations and guidelines have to be elaborated as an assistant description for user interested in introducing such a communication structure into industrial environment. 


\section{References}

[1] M.T. HOSKE: Industrial Networks. Control Engineering, http://www.controleng.com/article/CA6347555.html 2007.

[2] M. BREGULLA, W. FEUCHT: Wireless solutions in automation. ZVEI German Electrical and Electronic Manufacturers' Association, Frankfurt am Main 2011.

[3] YOKOGAWA: Wireless technology in industrial automation. SA Instrumentation \& Control, The Official Journal of the SAIMC, 2011, http://www.instrumentation.co.za/article.aspx?pklarticleid $=722451$.

[4] M. PAAVOLA: Wireless technologies in process automation-review and an application example. Control Engineering Laboratory, University of Oulu, 2007.

[5] NUREG/CR-6939, ORNL/TM-2006/86: Coexistence Assessment of Industrial Wireless Protocols in the Nuclear Facility Environment, Oak Ridge National Laboratory U.S. Nuclear Regulatory Commission Office of Nuclear Regulatory Research, Washington, DC 20555-0001 2012.

[6] M. ANDERSSON: Wireless technologies for industrial applications, http:/ /www.digikey.com/us/en/techzone/wireless/resources/articles/wireless-technologies-for-industrial-applications.html, 2011.

[7] J.S. LEE, Y.W. SU, C.C. SHEN: A Comparative study of wireless protocols: bluetooth, UWB, ZigBee, and Wi-Fi. Information \& Communications Research Labs Industrial Technology Research Institute (ITRI) Hsinchu. Proc. The 33rd Annual Conference of the IEEE Industrial Electronics Society (IECON), Hsinchu 2008.

[8] K.S. LOW, W.N WIN, J.E. MENG: Wireless sensor networks for industrial environments. Proc. Inter. Conference on Computational Modelling, Control and Automation, 2005 and International Conference on Intelligent Agents, Web Technologies and Internet Commerce, 2 (2005), 271-276.

[9] P. STENUMGAARD: EMC aspects for choosing wireless solutions in critical industrial applications. Proc. of Electronic Environment 2011, 37-38, Stockholm 2011.

[10] J. WERB, D. SEXTO: Improved Quality of Service in IEEE 802.15.4 Mesh Networks. Proc. Inter. Workshop on Wireless and Industrial Automation, San Fransisco, 2005, 1-6.

[11] P. ÄNGSKOG et al.: Sources of Disturbances on Wireless Communication in Industrial and Factory Environments. Proc. 2010 Asia-Pacific Symposium on Electromagnetic Compatibility \& Technical Exhibition on EMC RF/Microwave Meaurement \& Instrumentation, Beijing 2010.

[12] FLAMMINI et al.: Wired and wireless sensor networks for industrial applications. Microelectronics Journal, (2009).

[13] B. WAGNER et all: Location based wireless sensor services in life science automation. Proc. $4^{\text {th }}$ Inter. Conference on Real-world Wireless Sensor Networks, Springer-Verlag, Berlin-Heidelberg 2010, 82-93. 